\title{
Cuerpos recamados, cuerpos cosidos: Advertencia de uso para una máquina de coser de Eugenia Prado*
}

\author{
Mónica Barrientos ${ }^{* *}$ \\ Andrea Jeftanovic ${ }^{* * *}$
}

\begin{abstract}
Resumen
En este artículo se analizará el texto Advertencias de uso para una máquina de coser (2017), de la escritora chilena Eugenia Prado. El estudio se centrará en tres perspectivas: el taller de las operarias como espacio de precarización femenina, el cuerpo como soporte del dolor debido a la violencia laboral y, a la vez, como forma de escritura para revertir ese mismo poder, y finalmente, el cuaderno comunitario de la protagonista como una voz plural que denuncia y escribe. Estos aspectos serán desarrollados desde los conceptos de espacialidad, visualidad y el sentido comunitario bajo las propuestas de Henri Lefebvre, W. Mitchell y Jacques Luc-Nancy.
\end{abstract}

Palabras clave: Eugenia Prado, espacio, cuerpo, imagen.

\section{Bodies embroidered. Sewn bodies: Advertencia de uso para una máquina de coser by Eugenia Prado}

\begin{abstract}
This article will analyze the text of the Chilean writer Eugenia Prado Advertencias de uso para una máquina de coser (2017). This analysis will focus on three perspectives: the factory workshop of women workers as a space for female precariousness, the body as support for pain due to labor violence and, at the same time, as a form trough writing to reverse that same power; finally, the community notebook of the protagonist as a plural voice that denounces and writes. These aspects will be analyzed from the concepts of spatiality, visuality and community meaning under the proposals of Henri Lefebvre, W. Mitchell and Jacques Luc-Nancy.
\end{abstract}

Keywords: Eugenia Prado, Space, Body, Image.

\footnotetext{
* Agradecimientos al Proyecto Basal USA 1555 - Vridei 031751 JA-PUBLIC. Universidad de Santiago de Chile.

** Dra. en Literatura. Universidad Autónoma de Chile, Santiago, Chile. monica.barrientos@uautonoma.cl

*** Dra. en Literatura. Universidad de Santiago de Chile, Santiago, Chile. andrea.jeftanovic@usach.cl
} 
Con tanto ser humano que se cuela por los poros de una piel como la nuestra, habrá formas menos enervantes de ser y estar en este mundo.

(Eugenia Prado)

Para muchas mujeres a lo largo de la historia, las telas, las agujas, los hilos han sido parte de las primeras herramientas que han aprendido a usar. La máquina a pedal, los moldes hechos de papel de diario, los retazos de tela comprados en alguna oferta han producido fascinación en algunas que han podido pagar por diseños exclusivos, mientras que otras han visto en ellos la forma de poder vestirse o simplemente una fuente de trabajo.

El oficio de la costura, enseñado de madre a hija, de generación en generación, se convierte en trabajo precario cuando se traslada a un galpón con una veintena de operarias cosiendo prendas ajenas. Esto es lo que Eugenia Prado nos muestra en su última obra Advertencias de uso para una máquina de coser (2017) en la cual realiza una de las apuestas más interesantes sobre las tecnologías, maquinarias y técnicas antiguas propiamente femeninas como lo son la máquina de coser y sus utensilios.

Advertencias es un ejemplar raro y único. Cada texto está elaborado a mano, cada página ha sido confeccionada por la autora por medio de diseños propios, retazos de tela, fotografías antiguas, fragmentos de textos de los personajes y otros autores. Cada texto es un objeto de arte, una pieza única, tal como los moldes y prendas que las operarias deben coser en su diaria labor, como afirma desde el inicio: "Las mujeres nacíamos amarradas. Amarradas y calladas. Envueltas en géneros o enredadas en telas incomprensibles" (7). Esta reflexión sirve de apertura a los talleres en los que trabajan las mujeres donde conviven con las telas en forma laboral y el intercambio de experiencias en su vida personal.

Este artículo analizará el texto de Eugenia Prado centrándonos en tres perspectivas: el taller de las operarias como espacio de precarización femenina, el cuerpo como soporte del dolor debido a la violencia laboral $\mathrm{y}$, a la vez, como forma de escritura para revertir ese mismo poder; $\mathrm{y}$ finalmente, el cuaderno comunitario como una voz plural que denuncia y escribe.

En una entrevista con Carolina Gainza, Prado se define a sí misma cuando afirma:

Yo no vengo de la literatura y creo que eso hace que mi proyecto literario sea más personal o menos convencional. Mis proce- 
sos creativos y mi estructura de trabajo son otros. Leo, diseño, escribo, me comunico a través del computador. Trabajo temas distintos, soportes y programas distintos, casi todo el tiempo frente a la pantalla del computador, viajando de un lugar a otro. Me interesan las tecnologías y redes. Los cruces entre soportes, disciplinas. (s/p)

Esta visión y definición de sí misma es realmente acertada, ya que su obra no se puede encasillar en un formato o género determinado. Eugenia Prado es una escritora y artista visual que ha publicado diferentes obras narrativas como El cofre (1987), Cierta femenina oscuridad (1996), Lóbulo (1998) y Objetos del silencio (2007) reeditado en 2016. En su búsqueda menos convencional, el 2004 estrena su novela-instalación Hembros: asedios a lo post humano ${ }^{1}$, escénica plástica en el Galpón Víctor Jara. En el 2006 estrena Desórdenes Mentales, obra de teatro dirigida por Alejandro Trejo, y en el 2015 obtiene una Beca del Consejo del Libro CNCA para terminar su texto Asedios.

La obra de Eugenia Prado es diversa, múltiple y movible, es por ello que al leer Advertencias para el uso, su última novela y a la que dedicamos este trabajo, lo primero que llama la atención es su fuerte componente visual. Vemos fotografías antiguas, diseños de moldes, dibujos de máquinas de coser, patrones de tela y hermosos collages de instrumentos de costura y ginecológicos que muestran todo el potencial artístico de esta escritora y artista visual. Cada capítulo o apartado se divide en patrones de costura o en frases que engloban el contenido de la sección, formando una cartografía de este pequeño mundo. Algunos de ellos son: "La madre de la aguja es el punto que sangra", "El taller", "Las quejas", "Los plazos", "Las voces del taller" y "La libreta".

Para iniciar el análisis, ingresaremos al espacio del taller, a través del cual observaremos las condiciones laborales de las operarias y de qué forma este espacio es percibido e intervenido por los cuerpos de las mismas mujeres. Posteriormente analizaremos cómo estos cuerpos se convierten en la tela que modifican y alteran para formar un espejo deformado de la moda; y finalmente, el cuaderno comunitario de Mercedes, compuesto de imágenes y retazos de telas e historias como

Ver Eugenia Prado. Hembros: asedios a lo poshumano. Novela instalación. https://www.youtube.com/watch?v=3VluNranTck 
resultado de los atentados a la superficie de la tela y la página que las mujeres han escrito como una voz plural.

\section{Espacios precarios y simbólicos: el taller de costura}

Advertencias para el uso tiene como espacio principal el taller en que trabajan una serie de mujeres. Este lugar es descrito como un "observatorio de conductas" (10) donde la rutina de las costureras en la fábrica se presenta por medio de una cadena que une moda-espectáculo-cuerpos precarios dentro de una lógica neoliberal de exhaustivas jornadas de trabajo, como sucede con el personaje principal: "Mercedes sigue con atención los parámetros de la moda y cada vez más clara en sus ambiciones. Por ahora, sueña y se contenta con un pequeño tallercito ubicado en la parte de atrás de la casa y se amanece cosiendo por encargo, de otra forma, no habría podido costear la enfermedad de su madre" (27).

La reflexión sobre las relaciones entre las condiciones culturales y materiales acerca del trabajo estuvo dominada un largo tiempo por el binarismo cuerpo/alma como metáfora de lo laboral: la conversión física de la materia prima mediante un proceso que la transforma en un producto y, por el otro, las ideas, percepciones, sentimientos y valores encerrados en la mente de los trabajadores y patrones. El problema de este binomio como metáfora está en la dificultad para pensar sus relaciones, para construir vínculos que las unan en una sola estructura conceptual, entendiéndolas dentro de una misma realidad y no como aspectos separados sin una actividad simbólica. La producción material y simbólica van unidas, incluso entretejidas, ya que el trabajo más simple requiere un proceso mental en un determinado contexto cultural, por lo tanto, no existiría sin la materia prima de los símbolos, como Carlos Marx sostiene en un clásico pasaje de El capital:

$\mathrm{Al}$ consumarse el proceso de trabajo surge un resultado que antes del comienzo de aquél ya existía en la imaginación del obrero, o sea idealmente. El obrero no sólo efectúa un cambio de forma de lo natural; en lo natural, al mismo tiempo, efectiviza su propio objetivo, objetivo que él sabe que determina, como una ley, el modo y manera de su accionar y al que tiene que subordinar su voluntad. Y esta subordinación no es un acto aislado. Además de esforzar los órganos que trabajan, se requiere del obrero, durante todo el transcurso del trabajo, la voluntad 
orientada a un fin, la cual se manifiesta como atención. Y tanto más se requiere esa atención cuanto menos atrayente sea para el obrero dicho trabajo, por su propio contenido y la forma y manera de su ejecución; cuanto menos, pues, disfrute el obrero de dicho trabajo como de un juego de sus propias fuerzas físicas y espirituales. (cursivas en el original; 216)

De este modo, la noción de cultura del trabajo busca captar esta intersección entre lo simbólico y lo productivo. Se ubica en el espacio de las relaciones entre las dimensiones materiales y mentales de la actividad laboral. Sin embargo, debemos entender que, aunque todos los trabajos contengan esfuerzo físico, la producción simbólica de cada uno dependerá del tipo del trabajo y de quién ejecute la labor. Es por ello que el género y su función simbólica es un factor importante ${ }^{2}$.

La lucha del feminismo y las prácticas laborales dentro de lo que se ha llamado "capitalismo avanzado" han creado un escenario en que la mujer surge como "sujeto social", abriéndose caminos dentro de áreas académicas y laborales. La última década muestra un creciente aumento del ingreso de las mujeres al área pública y del trabajo asalariado. Sin embargo, a pesar de los nuevos espacios ocupados, los trasfondos simbólicos y culturales en relación a "la mujer" no han tenido grandes variaciones. Angeles Sánchez afirma que existen dos formas de conceptualizar el poder, aquella que define a la mujer como trabajo y aquella que la define como cuerpo (68). En la categoría de mujer-trabajo encontramos un enfoque político que entiende a la mujer como sujeto de estudios desde el análisis del marxismo, como vimos previamente, y dentro de la opresión sexual, quedando relegada al espacio privado de la casa y la familia. Con la incorporación de la fuerza femenina al trabajo, la división sexual del espacio público y privado queda en cuestión, ya que la actividad doméstica es asimilada a la producción social, manteniendo la desigualdad de la mujer como componente ideológico, como Sánchez (1986) afirma:

El desarrollo de esta contradicción en el capitalismo, una vez más queda subordinado a la cuestión de clase. En la medida

La pregunta por "la mujer" ha sido fuente de debate por muchos años. Carl Marx y Frederick Engels, establecían el origen de la opresión hacia la mujer con el surgimiento de la sociedad dividida en clases y la opresión era una parte integral del análisis desde el comienzo. Sin embargo, ambos pensadores sitúan a la mujer dentro del "contrato sexual” para la conformación de una sociedad monogámica que asegura los bienes y la herencia. Cf. Engels, Frederick. (Cap. II. "La Familia”) 
en que las mujeres se identifican con los intereses de la clase trabajadora están en posibilidad de cuestionar su condición subordinada, misma que únicamente quedará resuelta con la socialización de los procesos de producción. (71)

Es precisamente esta precarización del género lo que Prado nos muestra en el Taller de las operarias, donde "Unidas por hilos o separadas por filudas tijeras, espejos y botones, veinticinco operarias, trabajan en el enorme galpón" (9). En la descripción del espacio, el tiempo se ha detenido, ya que no podemos distinguir si se trata de un espacio laboral del siglo pasado o de nuestro presente:

Los grandes ventanales iluminan el recinto facilitando el trabajo durante el día, por las tardes, a medida que el sol decae, las mujeres irán desapareciendo a la luz de las ampolletas de bajo voltaje. En invierno, como en todas las construcciones antiguas, la energía disminuye y el frío y la humedad se condensan resbalando por las paredes, las ventanas y los vidrios. (11)

En Advertencias para el uso podemos observar cómo la producción material y la simbólica, que mencionábamos previamente, se representan en el grupo de mujeres que trabajan largas jornadas en un taller de ropa, un espacio vigilado del control del trabajo, pero a la vez, un espacioimagen que es percibido como "un observatorio de conductas y la mujeres, un todo por organizar" (10). Es un espacio capitalista, como afirmaría Henri Lefebvre, es decir, entendido como una relación social inherente a la relación de propiedad que se utiliza para producir plusvalía: "El espacio abstracto [que] revela sus capacidades opresivas y represivas en relación con el tiempo. Rechaza el tiempo como una abstracción (excepto cuando se trata del trabajo, del productor de las cosas y de la plusvalía). El tiempo se reduce a las limitaciones del espacio: horarios, carreras, travesías, cargas" (s.n).

El taller se presenta como una forma de panóptico para vigilar $\mathrm{y}$, al a vez, hacer productivos los cuerpos de las mujeres que "algo fundamental tienen en común, su trabajo se paga. Una vez al mes, se chequea la producción de la fábrica y se efectúan rigurosos exámenes y mediciones que confirman la resistencia de los cuerpos" (Advertencias 10). El salario a fin de mes está entonces supeditado por una rigurosa inspección invasiva que vigila los comportamientos y forma personas "útiles": "Nombre. Cargo. Oficio. Horas de producción. Cantidad de 
prendas defectuosas. Rendimiento máximo de operarias por turno" (10).

Otro factor importante en tiempos de globalización es que el crecimiento económico ha provocado cambios en los espacios urbanos, ya que, dentro de los mega centros de producción y consumo se encuentran, en un rango inferior, otros espacios que también aportan desde otra línea a la producción general. Estos espacios inferiores son más fáciles de detectar en los países "en vías de desarrollo" debido al abuso que se hace de ellos y es lo que Sasskia Sassen llama circuitos fronterizos que "son desarrollados por personas en condiciones de precariedad y bajos salarios, entre los que abundan mujeres y migrantes" (13). Estos circuitos fronterizos son diversos y se caracterizan por ser rentables para un grupo y generan beneficios para aquellos que se encuentran en desventaja. El fortalecimiento de estos circuitos es lo que permite un sistema económico global que provoca la presencia creciente de las mujeres en las economías en desarrollo, el aumento del desempleo y la deuda. En estos circuitos fronterizos, las mujeres son el grupo de mayor importancia, ya que su trabajo y uso cubre una gran variedad de "empleos" movibles y precarios, llamados "feminización de la supervivencia" (45), como sucede en el taller en nuestra obra, que concentra a un grupo diverso de mujeres: "En el taller están todas; las bravas, las desobedientes, las peleadoras, las que rasguñan y se rajan, las que se ganan el mejor puesto, la mejor luz" (10).

En esta misma línea, David Harvey (1993) afirma que el capitalismo marcha paralelamente con la reorganización espacial. Por un lado, el capital puede moverse libremente de un lugar a otro dentro de un espacio que ya contiene ciertas formas de relaciones; por otro, estos espacios se modifican por las nuevas tecnologías que alteran el carácter del lugar e interactúan con ese lugar en construcción. Por esto que el espacio y el tiempo en este relato tienen características especiales, ya que de pronto, sentimos que no estamos en un tiempo presente, sino que el tiempo se ha congelado. Las condiciones de trabajo en el taller son precarias y largas son las jornadas en que las mujeres permanecen sentadas al frente de la misma máquina de coser. Es por ello que llama la atención la transtemporalidad narrativa, por medio de la construcción del cronotopo -siguiendo los postulados de Bajtin ${ }^{3}$ - que se elabora a partir del taller

"En el cronotopo artístico literario tiene lugar la unión de los elementos espaciales y temporales en un todo inteligible y concreto [...] El tiempo se condensa aquí, se comprime, se convierte en visible desde 
de costura donde vemos elementos antiguos en formato vintage con tecnologías computarizadas, pero sobre todo la figura de la máquina de coser o "la Singer", metonimia de la marca de la máquina que todas las costureras han usado por décadas. Por lo tanto, el tiempo se condensa, ya que el lector no puede percibir si las mujeres que allí se encuentran son de otro siglo o si estamos en un presente actual.

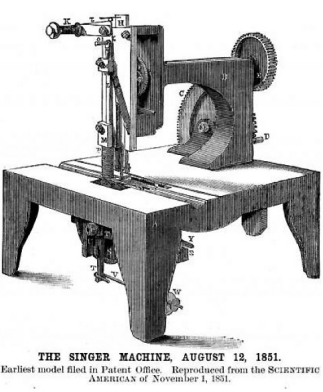

Imagen 1. "Géneros" (41).
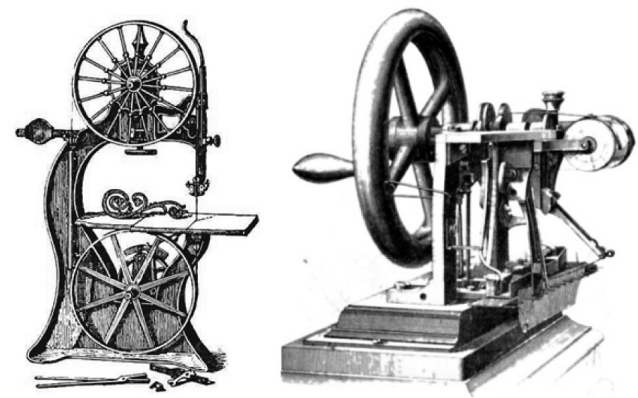

Imagen 2. "Agujas" (11). Imagen3. “Máquinas" (15).

La primera ilustración nos muestra una máquina de coser Singer antigua, acompañada del epígrafe "Géneros" , el cual explica como "artefactos creados por el hombre que define o reduce la fauna de animales humanos a dos géneros" (41). La segunda ilustración va acompañada del epígrafe "Agujas" que "sirve para atar una zona a otra" (11) y en la tercera, las "Máquinas", son definidas como "enjambres con que se enredan, arman o desarman los objetivos que operan en unión para productivizar o generar utilidad, actividad, desazón, ideologías y razones comunes" (15). El primer elemento que observamos en estas tres ilustraciones es la parodia del objeto definido. Recordemos que la parodia es un recurso que en la Antigüedad Clásica se relacionaba con la imitación burlesca. Sin embargo, con el tiempo se rescata como un recurso literario importante. Para Gérard Genette (1989), la parodia es el segundo grado de la literatura y "consiste en retomar literalmente un texto conocido para darle una significación nueva, jugando si hace falta y tanto como sea posible con las palabras [...]" (72). Para Severo Sarduy (1987) es un “operador de lo heterogéneo"(84) que rompe las reglas de

el punto de vista artístico; y el espacio, a su vez, se intensifica, penetra en el movimiento del tiempo, del argumento, de la historia. Los elementos del tiempo se revelan en el espacio, y el espacio es entendido y medido a través del tiempo. La intersección de las series y uniones de estos elementos constituye la característica del cronotopo artístico" (Bajtin 237). 
la norma, une diversos espacios, deforma las apariencias y multiplica los puntos de vista mediante diferentes vías de acceso. Finalmente Linda Hutcheon (2000) afirma que la parodia es una forma de imitación que se caracteriza por la "inversión irónica", y no necesariamente a través de un texto (6). Esta inversión irónica es muy importante para entender estas máquinas Singer definidas en el epígrafe, ya que permite la inversión de los elementos del código parodiado y muestra la dramatización de dicho código de modo que el lector pueda marcar una distancia entre lo parodiado y la parodia para interpretar y evaluar (31). Por lo tanto, para Hutcheon representa un factor fundamental la participación del lector, ya que sus herramientas extratextuales juegan un rol de coautoría de un texto que carece de centro y se configura como una aglomeración de voces.

En las tres ilustraciones vemos diferentes máquinas de coser que cumplen la misma función; sin embargo, la parodia se produce en la definición del objeto ya que, en el caso de la ilustración 1, el género al que se refiere no es la tela, sino los géneros sexuales, indicando firmemente que en este género "la mujer ha de poner su mayor empeño en esto de aprender a esperar el turno" (41). La "Aguja” de la ilustración 2 se refiere a atar zonas, no telas, mientras en la ilustración 3 , la máquina ha tenido un quiebre en el signo lingüístico, ya que el significado explota para traer otras máquinas, un "enjambre con que se enredan” (15), productoras de cultura, sea mecánicas o carnales. La parodia entonces quiebra el signo y el símbolo de la Singer para convertir estas máquinas de coser en máquinas sociales ${ }^{4}$, identificadas ya no solo con la técnica, sino con la naturaleza y los seres humanos como parte de un proceso de producción. El sistema capitalista produce y distribuye diferentes roles y funciones, mediante la fijación social, adjudicándonos una subjetividad y asignándonos una individuación basada en la identidad, sexualidad, profesión, nacionalidad, etc. Esta fijación tiene dos consecuencias: primero, nos constituye en sujeto siguiendo las exigencias del poder y, segundo, anuda a cada individuo a una identidad "fija". La Singer entonces es una metonimia de la sujeción de un sujeto femenino que es representado históricamente con el desarrollo de esta máquina de coser como máquina social perfectamente ajustada a un cuerpo femenino:

\footnotetext{
Recordemos que para Deleuze-Guattari, la máquina deseante definida por Freud como aquella que se encarga de producir deseo, también es una máquina social porque está al servicio de la producción de deseo como mecanismo social (Cfr. Deleuze, Gilles y Felix Guattari).
} 
La originalidad del capitalismo radica más bien en que la máquina social tiene por piezas las máquinas técnicas como capital constante que se engancha al cuerpo lleno del socius, y no a los hombres, que se han vuelto adyacentes a las máquinas técnicas (de donde que la inscripción ya no se realice, o al menos ya no debería necesitarlo en principio, directamente sobre los hombres). Pero una axiomática no es en modo alguno por sí misma una máquina técnica, incluso automática o cibernética. (Deleuze y Guattari 65)

El taller entonces, a través de este objeto que es la Singer, es un espacio-imagen movible. Esto significa que, a pesar de que las operarias trabajan en un contexto histórico determinado, la figura de la máquina ha cambiado con el tiempo, posiblemente ha mejorado sus funciones debido a las tecnologías, pero las condiciones de las trabajadoras son las mismas. La imagen de la máquina de coser es lo que Macarena Areco (2017) define como figuras y espacios que llama "lo imaginario", porque no solo dependen de lo evidente, sino que son

idea-figura-imagen construida por una sociedad específica, que se va formando y transformando de manera permanente, según las luchas de poder de las asociaciones humanas que detenta la hegemonía, la mantienen o la disputan, todo esto en un tiempo histórico siempre preciso, y al mismo tiempo siempre momentáneo. (43)

La Singer, máquina de coser y herramienta principal de las mujeres por muchos años, es una de estas "idea-figura-imagen" -como otras que veremos más adelante- que representan metonímicamente este espacio real vivido (el taller) percibido como lugar de observación y trabajo pesado, además de como lugar cotidiano donde es posible compartir con el otro. Debido al carácter movible que tiene "El Taller", se configura en una zona en el que, a pesar de ser altamente vigilada y estar al servicio de la producción, las mujeres que allí trabajan crean prácticas para alterar, sabotear o desestabilizar su propia estructura. El procedimiento que utilizan no es de rebeldía activa o frontal, sino más bien son pequeñas prácticas que reformulan el significado original de ese espacio. Es lo que De Certeau (1986) llama “estrategias de carácter táctico" que se ejecutan en el espacio del otro, acciones muy limitadas que carecen de poder porque no se ejercen sobre otros. Se trata sobre todo de estrategias 
de apropiación no hegemónicas que resignifican cosas ya existentes y el sentido de su uso. Dentro de estas tácticas, la perruque ${ }^{5}$ se refiere a pequeñas prácticas de sabotaje donde el trabajador usa el tiempo y las herramientas de trabajo para un beneficio personal:

En los lugares mismos donde impera la máquina a la cual debe servir, el trabajador se las ingenia para darse el placer de inventar productos gratuitos destinados únicamente a expresar, por medio de su obra, una pericia propia y a responder, por medio de un gasto, a las solidaridades obreras o familiares. Con la complicidad de otros trabajadores (que de este modo dan al traste con la competencia fomentada entre ellos por la fábrica), hace "jugadas" en el campo del orden construido. (De Certeau 31)

El taller se convierte entonces en el lugar móvil que, por un lado vigila, pero por otro lado es escamoteado por las mismas operarias que lo utilizan como lugar de consulta psicológica para hablar de sus problemas, sala ginecológica para abortos y espacio de creación de escritura, como veremos a continuación.

\section{Cuerpos (textuales) cosidos e imágenes de moda}

Este recorrido a través de las imágenes de la Singer permite comprender el binarismo como ordenamiento de lo social para pensar el género. Para ello hacemos referencia a los trabajos de Michel Foucault en torno las sociedades disciplinarias ${ }^{6}$ y la historia de la sexualidad. Aunque Foucault no abordó el tema del género y la vestimenta, sus propuestas sobre los cuerpos disciplinados se pueden relacionar con la historia del vestir en occidente. Numerosos trabajos de autoras feministas postestructuralistas, como por ejemplo, las propuestas de Judith Butler (2007) en El género en disputa, han incorporado la noción de poder esbozada por Foucault para explicar al cuerpo generizado como una construcción de la modernidad y del pensamiento binario, y de qué manera desmantelarlo.

En español se tradujo como "escamoteo".

Principalmente en Vigilar y castigar, Tecnologías del yo e Historia de la sexualidad, Foucault plantea que los dispositivos disciplinarios fueron constitutivos de la organización social capitalista en esta etapa a diferencia de los sistemas de encierro -con las metáforas del panóptico- más comunes en los siglos XVIII y XIX. 
El acceso por parte de la burguesía al dinero pero no al linaje fue determinante en la lucha por el prestigio social y los privilegios en el vestir. La aparición del capitalismo hizo que los lujos aparatosos perdieran sentido dando paso a la lógica de la distinción social, impuesto por un sistema de acicalamiento que lograba expresar los potenciales cambios internos en la estructura social y las nuevas identidades colectivas. Es aquí donde surge la moda propiamente tal, es decir, con constantes innovaciones de estilos estéticos y cambios en las jerarquías sociales. Este proceso estuvo acompañado por las transformaciones en el sistema productivo y en las tecnologías, transformando al trabajo de la industria fabril en el principal organizador de lo social. El estilo burgués rompió con estos hábitos e introdujo el gusto por el cambio constante en el vestuario. Los ciclos de la moda se adaptaron a los ritmos industriales y encontraron sociedades que absorbieron positivamente la democratización en el atavío y el consumo.

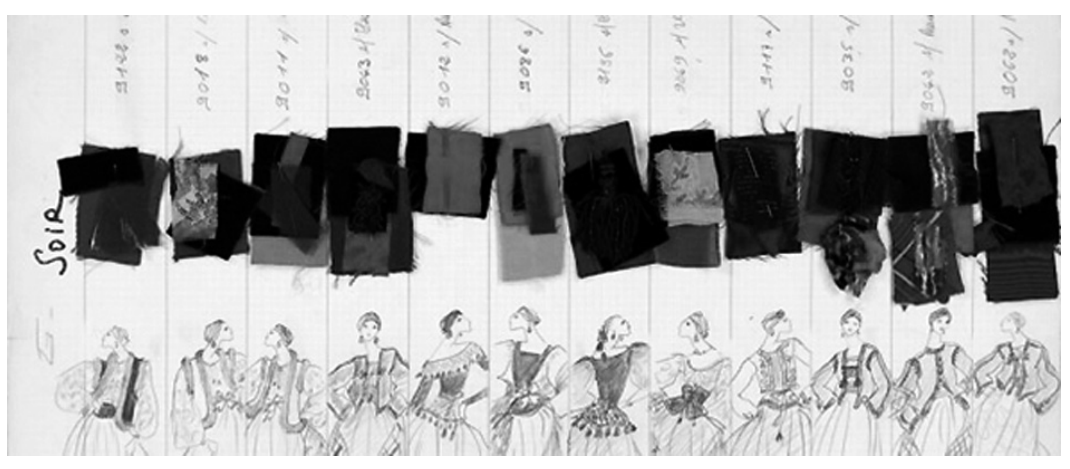

Imagen 4. (19).

Esta imagen en Advertencias de uso nos presenta una genealogía de la moda, donde cada boceto está relacionado a un tipo de tela o "género" con una especie de código. En la página, junto a la imagen, hay una pregunta que nuevamente se convierte en una parodia “ $i Y$ si uniéramos los textos como cuerdas y desbaratáramos los cierres para escapar de las celdas?" (20). Esta interrogante inmediatamente convierte este ciclo de la moda en una prisión que ya previamente se venía anunciando en las imágenes del libro, junto a la imagen del corsé femenino. Estas imágenes muestran una técnica disciplinaria y de opresión de los cuerpos de las mujeres, ya que esta prenda estaba relacionada a asuntos morales, dado que acentuar la cintura y levantar el busto, además de crear fetiches para 
la mirada de los hombres, impedía el movimiento del cuerpo, porque iban acompañados de una serie de adornos.

Es por ello que la imagen genealógica de las telas y el corsé que Eugenia Prado incluye en este texto son símbolos de normalización de los cuerpos femeninos, siendo el corsé un elemento estructurador del texto y los cuerpos:

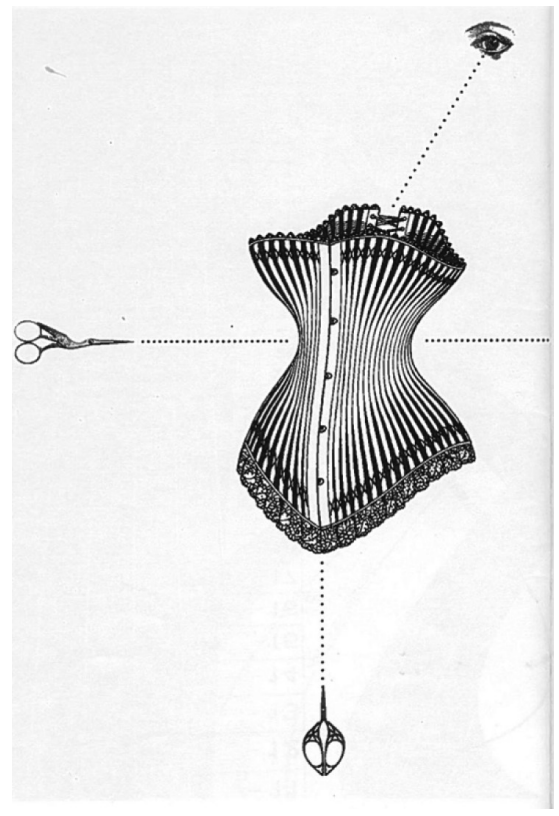

Imagen 5. (52).

En esta imagen observamos la figura de un corsé tradicional, pero que se encuentra intervenido por dos tijeras, una en el centro y otra desde arriba. En la parte superior, podemos ver un ojo panóptico que observa y se dirige directamente a la prenda. Esta ilustración es una introducción al capítulo "Modales de una costurera" que funciona nuevamente como parodia, ya que no se trata de las normativas que ellas deben seguir, sino de un procedimiento de aborto. La imagen y el capítulo simbolizan la intervención de los cuerpos femeninos por medio del vestuario, pero también como productor de fetos.

El vestuario entonces es un factor primordial en la configuración de identidades femeninas normalizadas y, por ende, la visualidad es también primordial para la construcción de identidades generizadas. Desde esta perspectiva teórica, el género es una tecnología al servicio de modelar 
los cuerpos a una heteronormatividad para diferenciarlos entre sexos y clase. A través de la corporalidad entonces se ejerce el control social de los sujetos desde el binomio masculino/femenino y, además, con el auge del capitalismo, la creación de clases sociales bien diferenciadas, como afirma Laura Zambrini (2010):

La emergente sociedad de clases impuso un sistema del vestir que lograba expresar los potenciales cambios internos en la estructura social y las nuevas identidades colectivas. En esta etapa surgió la moda propiamente dicha, es decir, con innovaciones permanentes de estilos estéticos y cambios relativos en las jerarquías sociales. Al modificarse el entramado social a causa del liderazgo de los valores burgueses, entre otros factores, posibilitó que tanto el dinero como los ideales de libertad e igualdad adquirieran un valor categórico. Este proceso estuvo acompañado por las mutaciones en el sistema productivo y en las tecnologías, transformando al trabajo de la industria fabril en el principal organizador de lo social. El crecimiento de las ciudades y la consecuente concentración de las poblaciones en las urbes, la necesidad de ampliar los mercados adónde vender lo producido, posibilitado a su vez por el intercambio de materias primas entre las colonias -especialmente en el rubro textil- fueron los impulsos necesarios para el desarrollo de la industria de la moda. (135)

Si bien aplica, en este caso, a la industria de la vestimenta o de la moda, podríamos extrapolarlo, por qué no, a la industria (re)productora de los hijos al servicio de la perversa macroeconomía social. De hecho, en Advertencias para el uso, una de las protagonistas nombra esto como "los deberes de la biología" (53), pensando en la obligación social de la maternidad y, ya más conscientes de su lugar en el mercado, comenta que "Nuestros cuerpos configuran una fuerza productiva poderosa (53)". Lo anterior lleva a pensar de inmediato en la posibilidad de interrumpir dicho proceso, ya sea en industria de trabajo, ya sea en el aborto y las consecuencias para las madres/trabajadoras: la cárcel o el despido. A lo largo del texto se puede observar las imágenes de tijeras, corsés, moldes, maniqués que metaforizan la intervención del cuerpo a través de las telas como herramientas de trabajo, pero también, al final del texto, en el capítulo "Otras prácticas femeninas" (59) vemos que, en ese espacio laboral, una serie de voces femeninas que preguntan sobre práctica medicinales para provocar un aborto. Es un gran murmullo en el cual 
una voz pregunta, otra responde, una opina, la otra obliga a callar. El murmullo se acrecienta para finalmente argumentar: "Entre las piernas se enhebra la vida. Apenas un hilván sobre la tela y dejamos de ser anónimas. Aprendemos a soltar amarras. Una vez cruzado el laberinto nadie puede castigarnos" (62)

En este punto es posible llegar a concluir que para Prado el control de la fuerza laboral es también metáfora del control del cuerpo: en ambos casos el cuerpo de la mujer es productor de capital y necesita ser controlado para asegurar el flujo y la estabilidad del mercado. Más que una huelga laboral, una huelga de vientres sería devastadora para la continuidad del sistema, en el sentido de que los intereses del capital están estrechamente ligados a las políticas de reproducción que aseguran un stock constante de sujetos productores/consumidores. De este modo, no es descabellado plantear que el ingreso de la mujer a la fuerza de trabajo es apenas una emancipación aparente que responde más bien a intereses bioeconómicos en la obra de Prado.

Es por esto que las operarias de la fábrica deben trabajar largas horas para la producción de ropa a causa de la necesidad de la moda y para el consumo ajeno. Ellas no visten las prendas que cosen, sino que solo son parte de un soporte mayor donde "en el entramado de todas estas piezas el taller es un observatorio de conductas y las mujeres, un todo organizado" (Prado 10). Sin embargo, ellas son capaces de resquebrajar ese espacio y a la máquina que las mantiene cosidas unas a otras para conformar una obra en común.

\section{El cosido de la imagen y la escritura comunitaria}

Hemos visto que el texto de Prado nos presenta una narración sobre las condiciones laborales de las operarias. Sin embargo, la narración no es el elemento principal, sino otra forma de relato que se conjuga con las imágenes del texto que hemos ido mostrando en este artículo. Es necesario indicar que la imagen no es un anexo o complemento a la narración, sino que funciona como otra forma de "relatar" la genealogía de las mujeres por medio de la imagen de la Singer, como lo vimos previamente, de la figura del corsé como metonimia de la modelización de los cuerpos femeninos y las telas como retazos que componen las vidas y del cuaderno de una de las operarias. Las imágenes, por lo tanto, funcionan en forma paralela para crear lo que hemos denominado anteriormente, la parodia. 
Desde esta perspectiva, entenderemos la imagen desde las propuestas de W. Mitchell acerca de la dicotomía palabra/imagen en la cual afirma que "las tensiones entre las representaciones visuales y las verbales no pueden desligarse de las luchas que tienen lugar en la política cultural y la cultura política" (11). Para entender las interacciones entre las representaciones visuales y verbales resulta determinante preguntarse ¿cómo son las imágenes?, ¿cuál es su relación con el texto? El giro pictorial que propone el autor designa un conjunto de cambios y transformaciones que está experimentando la sociedad, las ciencias humanas y la cultura pública. Estos cambios vienen de la mano de la creación de un nuevo repertorio de imágenes, por lo tanto, el giro pictorial se encuentra en los cambios de paradigma y en los cambios sociales y tecnológicos, aunque no está limitado solo a las nuevas tecnologías ni a la modernidad, sino que hay "giros pictoriales" desde la aparición de la fotografía que Benjamin venía postulando por medio del concepto de imagen dialéctica como imagen histórica que viaja del pasado hacia la actualidad. En esta misma línea, Didi-Huberman (2009) afirma que la imagen se entiende como subversión porque no se encuentra solo en el arte, para ello mezcla o "monta" metáforas que provienen de diversas fuentes (pintura, escultura, fotografías), construidas en "el detalle o fragmento" para contextualizarlas en un sentido diferente a la intención primera del autor, haciendo que la metáfora se convierta en un trazo epistemológico sobre el régimen de la imagen y no de esa imagen en particular: "todo depende de lo que se espere de él y de la manipulación a la que se someta" (La imagen superviviente 442). Es interesante observar que las imágenes en Advertencias de uso son montajes que la autora ha intervenido precisamente para mostrar el quiebre, la falla, la fisura en ese taller que simboliza la precariedad laboral y la normalización de los cuerpos de la mujeres a lo largo de la historia. Para Didi-Huberman, el carácter político de la imagen es precisamente por la "exposición" que ella misma contiene, no como espectáculo, sino en la descomposición de las dicotomías estructurantes porque permite pensar formas de comunicación fuera de las jerarquías de la información para “tomar posición” a pesar de los procesos normalizadores, de las lecturas lineales y de las políticas modernas:

una cosa es designar la máquina totalitaria y otra otorgarle tan rápidamente una victoria definitiva y sin discusión. [...] Es no ver más que la noche negra o la luz cegadora de los reflectores. [...] Es no ver más que el todo. Y es, por tanto, no ver el espa- 
cio -aunque sea intersticial, intermitente, nómada, improbablemente situado- de las aberturas, de las posibilidades, de los resplandores, de los pese a todo. (La supervivencia de las luciérnagas 31)

Es por ello que para analizar esta obra de Prado, debemos preguntarnos: ¿cómo se relaciona la imagen-texto en la obra?; ¿cómo se articula la letra y la imagen?; ¿qué efectos producen estas relaciones? Las probables respuestas darán cuenta de un proyecto escritural que cuestiona la pasividad de la letra y del lector -como espectador- que lo obliga a emanciparse de la estaticidad de la letra y moverse hacia el régimen visual de ésta. Esta movilidad es un gesto político necesario de la postura estética de la autora y del lector al poner en cuestión "el reparto de lo sensible" que Rancière (2009) nos advierte en la expresión "política de la literatura" que analizaremos más adelante.

El relato se mueve entre el pasado, el presente y el futuro, para reafirmar la continuidad del oficio de la costura como prisión y tortura, tanto para las mujeres que realizan el corte y la confección, como para aquellas que visten la prenda como moda instaurada dentro de una estética del consumo. Es por ello que las figuras de cuerpos femeninos nos mostrarán el relato de aquellos modificados por la moda, las tijeras y los patrones de costura. No son, por lo tanto, cuerpos hermosos elaborados, sino que intervenidos por los patrones de la moda. Vemos el reverso de las revistas, el proceso para llegar a ese "modelo ideal" del mercado:

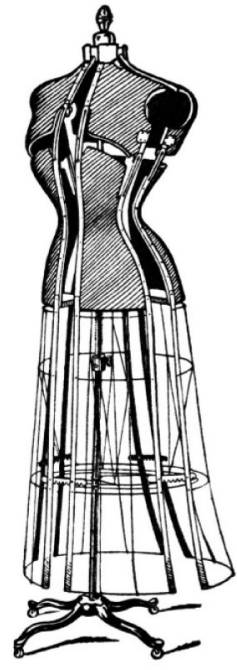

Imagen 6. (8).

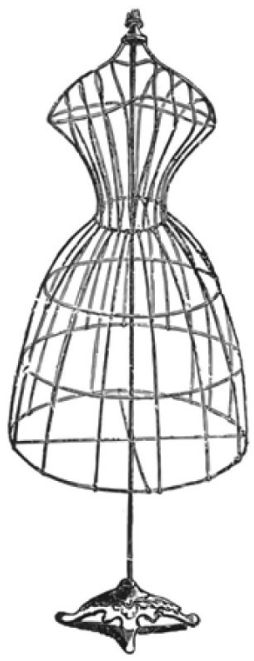

Imagen 7. (31).

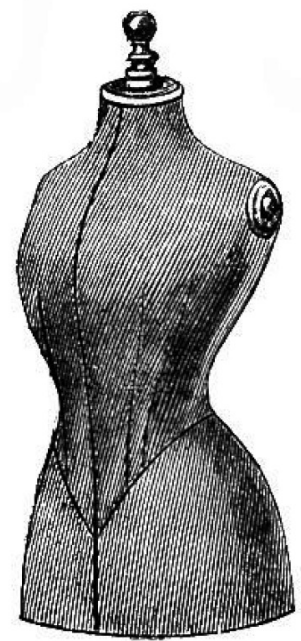

Imagen 8. (26). 
Estos moldes que se usaban para elaborar el vestuario femenino se asemejan a jaulas donde los cuerpos deben calzar. Además, estos moldes están intervenidos por tijeras y agujas, provocando un quiebre al uso práctico del objeto.

La fisura es entonces el elemento político que provoca el corte en el cuerpo, en los moldes y los modelos femeninos impuesto, así como el temblor en el espacio de la fábrica. Esta fisura la observamos en forma sutil a lo largo de toda la obra, ya que los moldes de las vestimenta se encuentran desarmados y las figuras de diferentes modelos de tijeras penetran las páginas que leemos, cortando las ilustraciones que se presentan como parodia del capítulo narrado, produciendo una compenetración absoluta entre texto, imagen y cuerpo de las operarias.

El capítulo "Las voces del taller" inicia la presentación de una genealogía de mujeres que han trabajado, sufrido y pinchado sus dedos en los talleres de costura, oficio aprendido de las madres y de las abuelas, primero como obligación por ser mujeres, luego para ayudar al sustento familiar, como afirma una de ellas: "Sigo el oficio de nuestras madres y abuelas y me siento heredera de sus dones. Soy ambiciosa y esforzada. Hago doble turno para que nada le falte a los míos" (Advertencias 25). Sin embargo, bajo ese orgullo, aparece el dedal como extensión del dedo que, si desaparece en la tela, provocaría el dolor por el ingreso de la aguja en la piel.

Cuando hablamos de comunidad, nos referimos a un espacio que permite la identificación múltiple, abierto hacia la heterogeneidad sin establecer fronteras, como un vacío diferencial fuera de los parámetros de la idea de seres idénticos que comparten rasgos en común. Es un espacio que se resiste a la representación política unitaria y que permite la emergencia de la otredad, de lo heterogéneo y lo residual como una forma de convivencia comunitaria en que la ausencia de identidad, de propiedad y de representación política no interviene en la preservación de lo múltiple, lo diverso, lo diferente. Se trata de un “estar" que Jacques Luc-Nancy (2000) llamó “comunidad inoperante" o "desobrada": "La comunidad es lo que tiene lugar siempre a través del otro y para el otro. No es el espacio de los "mí-mismos" [...] sino aquel de los yoes, que son siempre otros (o bien no son nada)" (38). Se trata de cuerpos y voces que comparten un espacio en común que las hace estar en comunidad. En las voces del taller vemos la conformación de una comunidad que intenta rearmarse a través de un oficio común 
heredado por otras mujeres por medio de la aguja y el hilo que las mantiene unidas para "hablar como si las vidas privadas no existieran, como si cada una pudiera diluirse en el paisaje de las demás. Como si fuéramos una misma voz con sus tiempos y cauces" (Advertencias 32). Este epígrafe introduce el capítulo "Haz tu propio cuaderno" en el que Mercedes, una de las operarias, interpela directamente a las otras mujeres también a escribir. Mercedes, tiene un cuaderno en el que narra todas las cotidianidades del taller, el sitio donde, "intuitivamente, Mercedes se deja guiar por la cadena de quejidos incómodos, como incómoda es la lengua que pulsa por transcribir imágenes y palabras que revolotean por su cabeza" (32). El cuaderno es un diario de vida, una libretade apuntes que va hilvanando con los retazos de historias de las otras mujeres, la historia de la máquina de coser, de la moda, ideas "descabelladas", ilustraciones: "El cuaderno de Mercedes es una caja de sorpresas. Contiene todo tipo de costuras sobre la piel, sobre la tela, sobre el papel, además de otros tipos de rarezas, escrituras, sobresaltos" (39). Este cuaderno, diario de vida, relación de apuntes de Mercedes que constituyen el libro que hemos estado leyendo, es el vehículo para la materialización de la perruque que habíamos nombrado previamente: la operaria tuerce el tiempo laboral de producción para su uso personal elaborando un cuaderno para su propio goce. Las puntadas en los dedos, los dolores de espalda, la irritación en los ojos por las largas jornadas de trabajo son recamadas en este cuaderno que confunde tela y piel, aguja y lápiz, escritura y cosido:

Paño / tela / carne / huella cuando se despliega, y deseosa la abierta, acóplase cuando su brecha expande.

Beso / tejido / labio pequeños roces ruborizados cuando se nutre, trenza, costura y carne. (42)

Escribir es entonces el sentido comunitario de estas operarias, ya que el cuaderno de Mercedes es la tela que reúne las voces, pero además es la incitación a la escritura, ya que el cuaderno sirve para que otras imiten este ejercicio como afirma la voz principal: "Se puede escribir de varias formas referidas al cuerpo, también hablar de las horas y horas trabajando en una misma posición y de nuestras vidas cosiendo para otros, puntada tras puntada relegadas a esas labores pero orgullosas del primer salario" (43). 


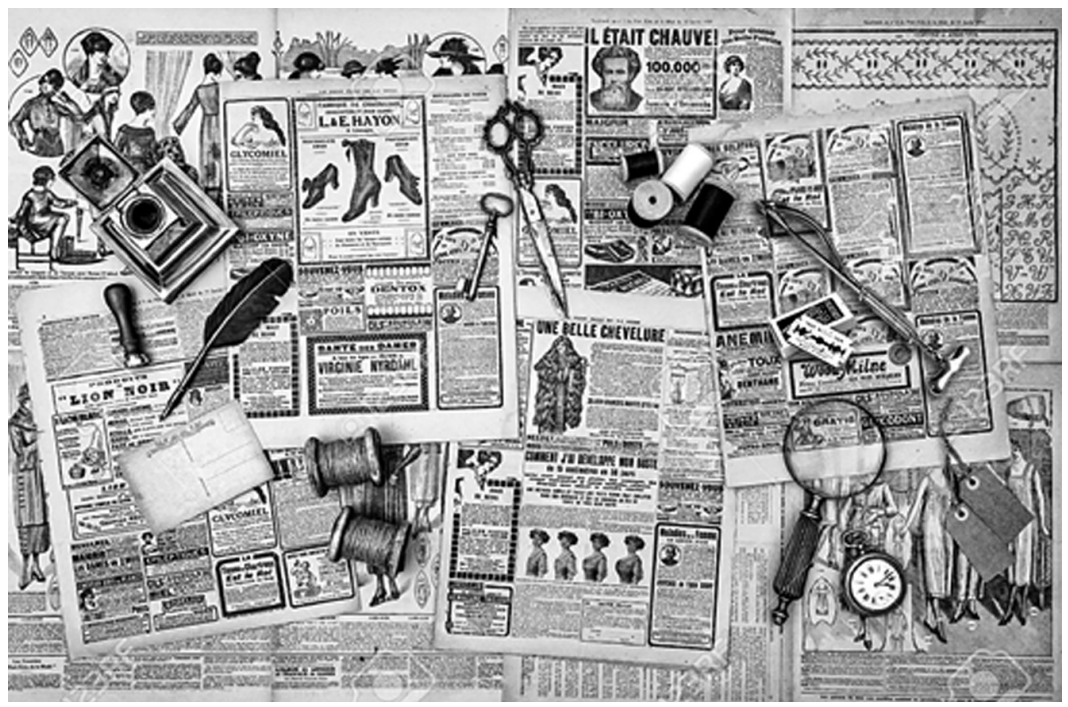

Imagen 8. (56-57).

Si escribir es la representación de las múltiples voces, la imagen es el hilo que conforma también este texto en un montaje. Didi-Huberman afirma que es una práctica de articulación a partir del diferencial temporal y posicional de los elementos en juego, como sucede en Advertencias de uso, donde las imágenes de las máquinas de coser, las tijeras, los hilos y los maniquíes de costura construyen una comunidad de montaje junto a la de voces y retazos del cuaderno, permitiendo una sobre-determinación de las imágenes que se abren a aquello que viene a interrumpir un orden de la historia lineal, acumulativo e irreversible, mostrando la temporalidad como indicio del anacronismo del texto:

El carácter político del montaje de la imagen y de su conformación comunitaria sirve para mostrar la escisión constitutiva que ambas contienen y no una muestra del antes y después de la historia. La práctica del montaje entonces reconoce el fin de la totalidad y la inestabilidad de la representación, y además se reconoce el desmontaje que muestra el carácter artificioso y no natural, procedente y no originario de su singular forma de estar-en-comunidad: "El montaje sería a las formas lo que la política es a los actos: necesita juntos estos dos significados del desmontaje que son el exceso de las energías y la estrategia de los lugares, la locura de la transgresión y la sabiduría de la posición" (DidiHuberman, Cuando las imágenes 153). 
La comunidad de la imagen y del montaje es una comunidad inoperante, sin identificación, pues huye de la idea de comunidad homogénea y opera desde lo fragmentario de sus componentes, pues se resiste a suturar los bordes cortantes de sus partes; no solo se compone de fragmentos, sino que sabe resguardar y cuidar de las costuras visibles que testimonian la no naturalidad del hilo, dejando ver el dispositivo, la contingencia de las puntadas que le dan consistencia. Por eso hemos leído y visto el cuaderno comunitario de Mercedes, con sus retazos, sus telas, sus historias cosidas por esa hebra de sangre que rompe la piel con cada puntada. Operarias productoras de moda, pero también de fetos que deciden, por libre voluntad, intervenir: cortar.

\section{Referencias bibliográficas}

“'Elegí Estar Fuera: Hay Una Rebeldía Que Se Está Moviendo. Sin Rebeldía No Hay Texto'”. Entrevista por Carolina Gainza. Laboratorio de Escrituras. Escuela de Literatura Creativa. Universidad Diego Portales., 08 de junio, 2017. 2016, http:// www.laboratoriodeescrituras.cl/elegi-estar-fuera-hay-unarebeldia-que-se-esta-moviendo-sin-rebeldia-no-hay-textos/.

Areco, Macarena. Acuarios y fantasmas. Imaginarios de espacio y de sujeto en la narrativa argentina, chilena y mexicana reciente. Santiago, Ceibo ediciones, 2017.

Bajtin, Mijail. Teoría y estética de la novela. Madrid, Taurus, 1989.

Butler, Judith. El género en disputa. El feminismo y la subversión de la identidad. Barcelona, Paidós, 2007.

De Certeau, Michel. La invención de lo cotidinano I. Artes de hacer. México, D.F., Universidad Iberoamericana, 1986.

Deleuze, Gilles y Félix Guattari. El Anti-Edipo. Capitalismo y esquizofrenia. Barcelona, Paidós, 1985.

Didi-Huberman, George. Cuando las imágenes toman posición. El Ojo De La Historia 1. Madrid, A. Machado Libros, 2008.

La imagen superviviente. Historia del arte y tiempo de los fantasmas según Aby Warburg. Madrid, Abada Editores, 2009.

La supervivencia de las luciérnagas. Madrid, Abada Editores, 2012. 
Engels, Friedrich. El Origen de la familia, la propiedad privada y el Estado. Venezuela, Ediciones La Cueva, s.r.

Genette, Gérard. Palimpsestos. La literatura en segundo grado. Traducido por Celia Fernándes Prieto. Madrid, Taurus, 1989.

Harvey, David. "From Space to Place and Back Again: Reflection on the Condition of Postmodernity". Mapping the Futures. Local Cultures, Global Change. Eds. Bird, Jon and Barry Curtis et al. New York. Routledge, 1993, pp. 2-29.

Hutcheon, Linda. A Theory of Parody. The Teaching of Twentieth-Century Art Forms. New York, First Illinois, 2000.

Lefebvre, Henri. "El espacio: producto social y valor de uso". Marxismo crítico. Praxis, conciencia y libertad. Accessed 22 de agosto, 2017. https://marxismocritico.com/2017/04/27/ el-espacio-producto-social-y-valor-de-uso/.

Mitchell, W.J.T. Teoría de la imagen. Ensayos sobre representación verbal y visual. Traducido por Yaiza Hernández. Madrid, Ediciones Akal S.A, 2009.

Nancy, Jean-Luc. La Comunidad Inoperante. Traducido por Juan Manuel Garrido. Santiago de Chile, LOM Ediciones, 2000.

Prado Bassi, Eugenia. Advertencias de uso para una máquina de coser. Santiago de Chile, Editorial Carnicera, 2017.

Rancière, Jacques. El reparto de lo sensible. Estética y política. Santiago de Chile, LOM, 2009.

Sánchez Bringas, Angeles. "Marxismo y feminismo: mujer-trabajo.” Nueva Antropología, vol. VIII, no. 30, 1986, pp. 67-76.

Sarduy, Severo. Ensayos generales sobre El Barroco. Buenos Aires, Fondo de Cultura Económica, 1987.

Sassen, Saskia. Contrageografías de la globalización. Género y ciudadanía en los circuitos transfronterizos. Madrid, Traficante de sueños, 2003.

Zambrini, Laura. "Modos de vestir e identidades de género: Reflexiones sobre las Marcas Culturales en el Cuerpo". Nomadías, no. 11, 2010, pp. 130-149, doi:10.5354/0719-0905.2010.15158. 